\title{
What Protects Adolescents from Suicidal Attempt: A Qualitative Study
}

\author{
Mohammad-Rafi Bazrafshan,,$^{, *}$ Fereidoun Jahangir, ${ }^{2}$ and Nasrin Shokrpour ${ }^{3}$ \\ ${ }^{1}$ Nursing Department, Larestan School of Medical Sciences, Larestan, Iran \\ ${ }^{2}$ Nursing Department, Shiraz University of Medical Sciences, Shiraz, Iran \\ ${ }^{3}$ English Department, Faculty of Paramedical Sciences, Shiraz University of Medical Sciences, Shiraz, Iran \\ "Corresponding author: Mohammad-Rafi Bazrafshan, Nursing Department, Larestan School of Medical Sciences, Larestan, Iran. Tel: +98-7152247110, Fax: +98-7152247111, E-mail: \\ mrbazr@sums.ac.ir
}

Received 2017 February 09; Revised 2017 April 22; Accepted 2017 May 20.

\begin{abstract}
Background: Suicidal attempts are common among adolescents around the world. Many countries have taken measures to reduce the high incidence of suicidal attempts and prevent people from killing themselves. They also provide care to accelerate the process of recovery among those who have attempted suicide.

Objectives: The aim of this study was to qualitatively evaluate the protective factors against suicidal attempts among adolescents who recently did so.

Methods: In this qualitative study, 18 single adolescents, with a mean age of $17.44 \pm 1.15$, who were referred to 2 hospitals in Shiraz (southern Iran), were selected via convenient sampling procedure. Data were collected via semi-structured in-depth interviews and analyzed using conventional approaches to qualitative content analysis.

Results: Three main categories and 10 sub-categories were extracted from the data. The main categories included: (a) individual factors (lack of mental conflict, religious beliefs, fear of death, thinking about family, hope for the future, spiritual counseling), (b) social factors (interaction with friends, social stigma of suicidal attempt, sense of family cohesion), and (c) professional advice and support (psychological counseling).

Conclusions: The findings of this study can guide health professionals to take measures to prevent suicidal attempts, communicate with people who are at risk of attempted suicide, and prevent relapse of those who are in recovery period after an attempted suicide.
\end{abstract}

Keywords: Adolescent, Content Analysis, Protective Factors, Qualitative Research, Suicide Attempt

\section{Background}

Suicidal attempt refers to involvement in potentially self-injurious behavior with a non-fatal outcome and an evidence of the persons' tendency to die (1). Suicide theories cover various viewpoints such as biological, psychodynamic, cognitive-behavioral, and developmental/systems. Among these theories, developmental/systems theories play a key role in upset social forces (2). Many of Durkheim's assumptions, one of the most well-known theorists of suicide in the late 19th century, were based on developmental/systems model $(2,3)$. The important role of social factors in the etiology of suicidal attempt was highlighted by Durkheim $(2,4,5)$. According to Durkheim's theory (1897), disorganization of social forces leads to suicidal attempt. He suggested that the lack of social integration besides moral integration leads to a rise in suicide attempts $(2,4,6)$. He argued that social ties can protect the individuals against suicidal behavior by social integrations and moral regulations (5). Due to the importance of the suicide attempt issues, rates of suicidal attempts are among important indicators of a community's mental health $(7,8)$. According to estimates by the world health organization, in the year 2020, approximately 1.53 million people will die from suicide and at least 10 times more people will attempt suicide worldwide. This is on average 1 death every 20 seconds and 1suicidal attempt every 1 - 2 seconds $(9,10)$. In Iran, suicide attempts have become increasingly important. The suicide attempt rate in our country is higher than the majority of Muslim countries (11). Recently, the rate of suicide attempts in Southern Iran has increased and the age of people who attempt suicide has declined (12-14). A review of previous studies suggests that adolescence is a critical period for initiating selfinjurious behavior (15). Suicidal attempts in adolescents are accompanied by different results, such as disability and increased costs of treatment in this population $(16,17)$. In addition, the suicide attempt in adolescents is a dramatic event, but it is avoidable (18). Unfortunately, few studies have been carried out in Iran for a comprehensive understanding of suicide attempts and suicide prevention with regard to the Iranian culture (19). Furthermore, few qualitative studies have been carried out in the socio-cultural context of our country regarding protective factors against suicidal attempts among adolescents; there may be issues less addressed by available literature. Therefore, it is necessary to investigate protective factors against suicidal at- 
tempts among adolescents with regard to socio-cultural characteristics and conditions in our country.

\section{Objectives}

Our study was carried out to investigate the protective factors against suicidal attempts among adolescents who recently attempted suicide. The results of this study can help the related authorities coordinate their activities in order to meet the needs of this age group.

\section{Methods}

Qualitative content analysis was used in this study to investigate protective factors against suicidal attempts among adolescents. One of 3 approaches for the qualitative content analysis method is a conventional qualitative content analysis. In this approach, coding categories are derived from the raw data directly and inductively without imposing predetermined categories or theoretical perspectives on them (20).

Eighteen adolescents ( 6 males and 12 females) aged 16 to 19 years, who were referred to 2 hospitals in Shiraz, from September 2013 to June 2014, after attempting suicide with drugs, agreed to participate in this study.

In the first step, the adolescents visited hospitals for establishing a close rapport with them and determining an appropriate time for an interview. In the second step, interviews were conducted 48 to 120 hours after the participants were discharged from the hospital. Based on their medical condition, ability, and interest, the time for interviews was determined.

The participants who had one of the inclusion criterias, such as inability to participate in the study for any reason expressed by them like lack of interest or diagnosis with severe depression and acute psychosis. Convenient sampling method was carried out and continued until data saturation was reached.

Each interview was started by introducing the interviewer and explaining the purpose and method of the study. Data were collected using semi-structured in-depth interviews. A general question (How do you describe a day in your life?) was the first question and then the interview continued with follow-up questions. Finally, the interviewer asked the participants to discuss other important issues that were not mentioned during the interview. A calm and quiet place was chosen for convenience of the participants during interviews. Each participant was interviewed during 1 session. The mean duration of the interview was almost 54 minutes.

Collecting and analyzing data were done simultaneously. For the analysis, first, each interview was recorded.
After listening to it several times, the interview was typed verbatim and then entered into MAXQDA 10 . In the software, every interview was read word by word and each text was broken into meaning units. Then, similar meaning units were grouped in 1 category. Finally, based on the content and similarities, the main categories were formed by using subcategories. After each interview and throughout the data analysis, the researchers wrote theoretical memos that were then coded. This contributed to the richness of the data. The main categories were summarized in 3 themes.

To improve the accuracy and rigor of the findings, Lincoln and Guba's (1985) criteria were used (21). To increase the credibility of data, a prolonged engagement with the data collection process and analysis was kept.

The data were collected from 2 major referral hospitals where the participants had been admitted. The memos were written by the interviewer and the accuracy of the data analysis was confirmed by 3 specialists in the field of qualitative research. Finally, original codes were checked by some participants to compare the findings with the participants' experiences.

To increase the dependability and conformability of data, maximum variation was observed in the sampling. Finally, to increase the power of data transferability, adequate description of data was provided in the study for critical review of the findings by other researchers.

All participants and their parents signed the informed consent prepared in accordance with the Helsinki Declaration.

\section{Results}

The mean age of the adolescents in this study was 17.44 \pm 1.15 , all being single. Three main categories and 10 subcategories of data were obtained (Table 1).

\subsection{Individual Factors}

Protective factors of a suicidal attempt can begin at the individual level (22). Many studies have been carried out on suicide attempt risk factors. However, many people exposed to suicide attempt risk factors show no suicidal attempt tendencies. Thus, these people have capabilities, which are missing in individuals who attempted suicide. Observations show that there may be protective factors as coping strategies in individuals that decrease the risk among this age group $(23,24)$.

In this study, individual factors consist of the subcategories of lack of mental conflict, religious beliefs, fear of death, and thinking about family, hope for the future, and spiritual counseling. 
Table 1. Summary of the Study Findings

\begin{tabular}{ll}
\hline Main Categories & Sub-Categories \\
\hline Individual factors & Lack of mental conflict, religious beliefs, fear of death, thinking about family, hope for the future, spiritual counseling \\
Social factors & Interaction with friends, the social stigma of suicide attempts, sense of family cohesion \\
Professional counseling and support & Psychological counseling \\
\hline
\end{tabular}

To deal with their stress, these participants used methods to divert their attention from the main problem. Such methods included listening to music, studying, working, participating in extracurricular classes, and leaving home.

One participant said: “... once upon a time, I was in love and I lost my love and I was hurt so badly ... I was trying to forget this subject, but I thought about death ... I'm so afraid of falling in love again ...”.

Another participant said “... When unpleasant emotions come to my mind, I think about my goals such as Concour (University Entrance Exam) and I try to focus on my pre-university courses....".

Another participant added: “... To forget that I have problems, I try to entertain myself with different things, like working in my father's shop. That evening I did not go to my father's shop ... Bad thoughts came to my mind, I wanted to escape from them,but problems were stronger...".

Also, one participant said: “... I love art because it suits my mood, especially calligraphy ... when I am tired and bored, I practice bad ideas springing my mind, such as black lines and tangled...”.

No doubt, religious beliefs play a significant role in preventing suicidal attempts. One of the participants said: “... I am a Muslim; I know it is not right for a man to commit suicide and even thinking about it is not true ... But it seems, I am not a good slave for God...”.

To be able to end one's life, one must overcome the natural fear of death. Thus, giving up on a suicidal attempt can be due to the natural fear of death. One of the participants said: “... I thought about suicide, but I was afraid because I was scared of death. Death is the end of everything...".

Adolescents' attention to their family because of their close relationship with parents can be a strong factor in preventing suicidal attempts. In this regard, one participant said: “... That night I had an argument with my father about my friends... I wish to die to be saved from the frequent argument..... But I knew for my dad my happiness was important... I love my dad...”.

Another participant said: “... When the Concour (University Entrance Exam) results were announced, I was not admitted in my favorite discipline ... I was hopeless and my parents were sad ... They had labored for me and they were hopeful about me...".

Hope of future and setting goals in life can protect adolescents against suicidal ideation. One participant said: “... I'm motivated to have a good job in the future.... I try hard to continue my education in future and achieve high positions ...".

Strengthening people's spiritual dimension can be as important and effective as psychological counseling. In this regard, one of the participants said: “... formerly, I used to go to the mosque and attend the meetings by clergyman ... those times I felt better because I was closer to God ... I miss those times ... I must go back to God... God is merciful and forgiving...".

\subsection{Social Factors}

The influential role of social factors in the etiology of suicide attempt was highlighted by Durkheim $(2,5,6)$. One of the common themes from sociological theories regarding suicide attempts is the fact that positive social connections may protect individuals against suicide attempts, whereas negative social connections may enhance the risk of suicide attempt $(4,5)$. In other words, social context is a crucial factor in understanding the risk of suicide attempt (25). In this study, this category includes interaction with friends, the social stigma of suicide attempts, and sense of family cohesion.

Interaction with other members of the society can be effective in deterring suicidal ideation. In this regard, one participant said: “... I am forced to go to military service, while I like to go to university and I am always preoccupied about it; my encouragement is my family support and my happiness is having fun with friends ...”. Another participant mentioned “...I have a very good relationship with my family, especially my mother ...thinking about my family caused discouragement and killing myself ...”.

The suicidal attempt is an abomination in society and the society's negative attitude towards such people can decrease suicidal attempts. In this regard, one participant said: "... the mouth of the people cannot be closed ... people's condemnation has been added to my problems ...". 


\subsection{Professional Counseling and Support}

Suicidal symptoms, risk, and behaviors are common among patients in mental health centers due to the prevalence of mental disorders and other risk factors (26). There is some evidence, which indicates receiving professional support, that plays a significant role in preventing suicidal attempts (27-29). Therefore, mental health professionals, particularly those in school settings, need to get involved in screening such individuals to help reduce suicide and non-fatal suicidal behavior among adolescents (30).

This category includes psychological counseling. Many people who have attempted suicide had not received psychological counseling before doing so. Strengthening the psychological dimensions of such individuals by professionals in the fields can increase their tolerance for the problems. One participant who attempted suicide after love failure, said: “... Prior to hospitalization, I thought referring to psychologist or a psychiatrist means that man must be crazy ... I am not crazy ... But now I know, I have many problems and I need help ... and that their professional approach and advice are based on science and compassion...".

\section{Discussion}

In this study, protective factors against suicidal attempt among adolescents were studied. Suicidal attempt is a cry for help. Therefore, this has a positive potential towards treatment and re-adjustment $(31,32)$. This movement should certainly start with the person himself/herself. The methods these people used to keep away from suicidal ideation included self-control of suicidal thoughts and self-actualizations via working, exercise, and study. In this way, the person tries to ward off negative thoughts to put off the decision to attempt suicide $(19,23)$. Research stresses the effects of patient-centered measures such as encouraging them to get busy by doing things of personal interests such as working, exercise, and watching TV. Families who take such measures to care for people who attempted suicide will have a better chance of recovery than those who do not for various reasons such as lack of information on taking care of these patients (33).

The role of religion in prevention of suicide has been mentioned in numerous studies. Lack of religious beliefs can diminish the hope of improving conditions (19, 31, 3336). It is, therefore, essential that counselors consider psychological as well as spiritual dimensions.

Research suggests an inverse relationship between fear of death and suicidal attempt so that people who are afraid of death are less likely to report suicidal ideation (37, 38).
Family problems such as conflict with parents and other family members are the most important causes of suicidal attempts among adolescents (39-41). On the contrary, sense of family cohesion, emotional support from the family, and a warm relationship between family members are among the most important protective factors against suicidal attempt by adolescents $(19,31,42)$. Emile Durkheim demonstrated that suicide attempt rates were higher in populations that were less cohesive in family. For Durkheim, social cohesion, especially traditional life, provided the best protection against self-destructive behavior (43). Therefore, when adolescents think about their families and how they will be affected by their attempted suicide, they are likely to abandon such ideation.

When adolescents are faced with problems in their lives, they show some emotional reactions, the most common form of which is a sense of hopelessness (41). Research suggests that psychological characteristics such as hopelessness increase the risk of suicidal ideation $(38,40)$. On the other hand, valuing life and having hope for the future can be protective factors against suicide attempts (19).

Community members such as friends play an important role in the prevention of suicidal attempts among adolescents. Adolescents are at a period of life in which they are affected by their peers significantly. Therefore, friends can have a role in changing the adolescents' attitudes and prevent their suicidal attempts $(19,31)$. Negative attitudes towards suicide attempts in the society and a person's consideration of what will be said about him/her after suicide attempt can prevent him/her from doing so $(37,38)$.

Durkheim's adherence to a theoretical framework that considered social relationships as a protective factor against suicide attempt (5). A common theme from sociological theories regarding suicide attempts is the fact that positive social connections may be protective against suicide attempts, whereas negative social connections may enhance the risk of attempt suicide $(4,5)$. According to Durkheim's theory (1897), the outcome of disorganization of social forces is attempting suicide. He suggests that too little social integration as well as too little moral integration leads to a rise in suicide attempt $(2,4,6)$. He argued that social ties can protect the individuals against suicidal behaviors by integrating them into society and providing them with moral regulation (5).

There is some evidence that indicates that receiving professional support plays a significant role in preventing suicidal attempts (27-29). Yet, most people, who have committed suicide, had not received the special psychological care before death (44). In the same line with other studies, the present study showed that some individual characteristics are the reasons why individuals and families do not seek professional help at times of trouble. These in- 
clude help-resisters by nature, attempt to solve the problem without the help of others, fear of medication, lack of recognition of the problem by family, lack of awareness, and social stigma of mental illness $(28,45)$.

Suicidal behavior is generally not accepted, especially in societies like Iran, where people have strong religious beliefs. Many people who are seeking help in various areas seek help from the clergymen. One of the areas where people do so is suicidal behaviors. Therefore, clergymen can be the first ones to help these distressed individuals. These people, along with health professionals play a critical role in preventing suicide attempts $(46,47)$.

\subsection{Conclusion}

The results of this study show that although there is no doubt that improving the individual's health plays a role in preventing suicidal attempts, a comprehensive approach is needed in programs designed to prevent it. In this regard, in addition to especial attention to individual factors, other factors such as family, social background, professional advice, and care they receive should be considered.

\subsection{Limitations}

Limitations of this study include: selection of subjects only from among the adolescents referring to hospitals, difficulty of finding participants due to the social stigma of suicidal attempts, and caution in generalizing the findings to the population due to the nature of the qualitative research.

\section{Acknowledgments}

The present article was financially supported by Shiraz University of Medical Sciences (Grant No. 87-4437). The researchers would like to thank all research participants who have contributed to the study.

\section{Footnotes}

Authors' Contribution: Mohammad-Rafi bazrafshan developed the study design, conducted the interviews and analysis, ensured trustworthiness and drafted the manuscript; Fereidoun Jahangir and Nasrin Shokrpour revised the manuscripts.

Funding/ Support: This study was supported by Shiraz University of Medical Sciences, Shiraz, Iran.

Financial Disclosure: There are no conflicts of interest in financial issues with any individual or third party.

\section{References}

1. Nock MK, Borges G, Bromet EJ, Cha CB, Kessler RC, Lee S. Suicide and suicidal behavior. Epidemiol Rev. 2008;30:133-54. doi: 10.1093/epirev/mxn002. [PubMed: 18653727].

2. Van Orden KA, Witte TK, Cukrowicz KC, Braithwaite SR, Selby EA, Joiner TE. The interpersonal theory of suicide. Psychol Rev. 2010;117(2):575600. doi: 10.1037/a0018697. [PubMed: 20438238].

3. Travis R. Halbwachs and Durkheim: a test of two theories of suicide. BrJ Sociol. 1990;41(2):225-43. [PubMed: 2386880].

4. Fassberg MM, van Orden KA, Duberstein P, Erlangsen A, Lapierre S, Bodner E, et al. A systematic review of social factors and suicidal behavior in older adulthood. Int JEnviron Res Public Health. 2012;9(3):72245. doi: 10.3390/ijerph9030722. [PubMed: 22690159].

5. Mueller AS, Abrutyn S, Stockton C. Can Social Ties be Harmful? Examining the Spread of Suicide in Early Adulthood. Sociol Perspect. 2015;58(2):204-22. doi: 10.1177/0731121414556544. [PubMed: 26120243].

6. You S, Van Orden KA, Conner KR. Social connections and suicidal thoughts and behavior. Psychol Addict Behav. 2011;25(1):180-4. doi: 10.1037/a0020936. [PubMed: 21142333].

7. Martinelli Boneschi F, Comi G. Assessing Functional Decline in Neurological Diseases Clinical Trials: Duration of Follow-Up - The Case of Multiple Sclerosis. Front Neurol Neurosci. 2016;39:93-100. doi: 10.1159/000445418. [PubMed: 27463522].

8. Sagawa Y, Magnin E, Paillot L, Moulin T, Decavel P. Fampridine and quality of life in individuals with multiple sclerosis. Springerplus. 2016;5(1):1070. doi: 10.1186/s40064-016-2776-2. [PubMed: 27462518].

9. Son JH, Lee SH, Seok JW, Kee BS, Lee HW, Kim HJ, et al. Virtual Reality Therapy for the Treatment of Alcohol Dependence: A Preliminary Investigation With Positron Emission Tomography/Computerized Tomography. J Stud Alcohol Drugs. 2015;76(4):620-7. [PubMed: 26098039].

10. Strunz F. [The will to meaning in dreams-the dream as the will to meaning]. Wien Med Wochenschr. 1991;141(7):129-32. [PubMed: 2058159].

11. Shirazi HR, Hosseini M, Zoladl M, Malekzadeh M, Momeninejad M, Noorian K, et al. Suicide in the Islamic Republic of Iran: an integrated analysis from 1981 to 2007. East Mediterr Health J. 2012;18(6):607-13. [PubMed: 22888617].

12. Morris LD, Louw QA, Grimmer KA, Meintjes E. Targeting pain catastrophization in patients with fibromyalgia using virtual reality exposure therapy: a proof-of-concept study. J Phys Ther Sci. 2015;27(11):3461-7. doi: 10.1589/jpts.27.3461. [PubMed: 26696719].

13. Mahdizadeh M, Alavi M, Ghazavi Z. The effect of education based on the main concepts of logotherapy approach on the quality of life in patients after coronary artery bypass grafting surgery. Iran J Nurs Midwifery Res. 2016;21(1):14-9. doi: 10.4103/1735-9066.174752. [PubMed: 26985218].

14. Ghanizadeh A, Nouri SZ, Nabi SS. Psychiatric problems and suicidal behaviour in incarcerated adolescents in the Islamic Republic of Iran. East Mediterr Health J. 2012;18(4):311-7. [PubMed: 22768691].

15. Ferrara M, Terrinoni A, Williams R. Non-suicidal self-injury (Nssi) in adolescent inpatients: assessing personality features and attitude toward death. Child Adolesc Psychiatry Ment Health. 2012;6:12. doi: 10.1186/1753-2000-6-12. [PubMed: 22463124].

16. Lohse KR, Hilderman CG, Cheung KL, Tatla S, Van der Loos HF. Virtual reality therapy for adults post-stroke: a systematic review and metaanalysis exploring virtual environments and commercial games in therapy. PLoS One. 2014;9(3):e93318. doi:10.1371/journal.pone.0093318. [PubMed: 24681826].

17. Viana RT, Laurentino GE, Souza RJ, Fonseca JB, Silva Filho EM, Dias SN, et al. Effects of the addition of transcranial direct current stimulation to virtual reality therapy after stroke: a pilot randomized controlled trial. NeuroRehabilitation. 2014;34(3):437-46. doi: 10.3233/NRE-141065. [PubMed: 24473248]. 
18. Law FM, Guo GJ. The impact of reality therapy on self-efficacy for substance-involved female offenders in Taiwan. Int J Offender Ther Comp Criminol. 2015;59(6):631-53. doi: 10.1177/0306624X13518385. [PubMed: 24420638].

19. Keyvanara M, Mousavi SG, Malekian A, Kianpour M. Suicide prevention: The experiences of recurrent suicide attempters (a phenomenological study). Iran J Psychiatry Behav Sci. 2010;4(1):4-12.

20. Hsieh HF, Shannon SE. Three approaches to qualitative content analysis. Qual Health Res. 2005;15(9):1277-88. doi:10.1177/1049732305276687. [PubMed: 16204405].

21. Lee SJ, Chun MH. Combination transcranial direct current stimulation and virtual reality therapy for upper extremity training in patients with subacute stroke. Arch Phys Med Rehabil. 2014;95(3):431-8. doi: 10.1016/j.apmr.2013.10.027. [PubMed: 24239790].

22. Copeland-Linder N, Lambert SF, Ialongo NS. Community violence, protective factors, and adolescent mental health: a profile analysis. J Clin Child Adolesc Psychol. 2010;39(2):176-86. doi: 10.1080/15374410903532601. [PubMed: 20390809].

23. Bazrafshan MR, Jahangir F, Mansouri A, Kashfi SH. Coping strategies in people attempting suicide. Int J High Risk Behav Addict. 2014;3(1):16265.

24. Beautrais AN. Suicide in New Zealand II: a review of risk factors and prevention. Z Med J. 2003;116:1175.

25. Hjelmeland $\mathrm{H}$. Cultural context is crucial in suicide research and prevention. Crisis. 2011;32(2):61-4. doi: 10.1027/0227-5910/a000097. [PubMed: 21602160].

26. Pisani AR, Cross WF, Gould MS. The assessment and management of suicide risk: state of workshop education. Suicide Life Threat Behav. 2011;41(3):255-76. doi: 10.1111/j.1943-278X.2011.00026.x. [PubMed: 21477093].

27. Suominen K, Isometsa E, Martunnen M, Ostamo A, Lonnqvist J. Health care contacts before and after attempted suicide among adolescent and young adult versus older suicide attempters. Psychol Med. 2004;34(2):313-21. [PubMed: 14982137].

28. Owens C, Lambert H, Donovan J, Lloyd KR. A qualitative study of help seeking and primary care consultation prior to suicide. BrJ Gen Pract. 2005;55(516):503-9. [PubMed:16004734].

29. Alavi A, Sharifi B, Ghanizadeh A, Dehbozorgi G. Effectiveness of cognitive-behavioral therapy in decreasing suicidal ideation and hopelessness of the adolescents with previous suicidal attempts. Iran J Pediatr. 2013;23(4):467-72. [PubMed: 24427502].

30. Joe S, Bryant H. Evidence-Based Suicide Prevention Screening in Schools. Child Sch. 2007;29(4):219-27. [PubMed: 21113412].

31. Obando Medina CM, Dahlblom K, Dahlgren L, Herrera A, Kullgren G. I keep my problems to myself: Pathways to suicide attempts in nicaraguan young men. J Suicidol. 2011;2:17-28.

32. Jahangir F, Bazrafshan MR, Zangoee AR, Raeisi T. Comparison of coping mechanisms used by suicidal attempt patients, and those without suicidal history. 2009 ;13(2):109-13.

33. Sun FK, Long A, Huang XY, Huang HM. Family care of Taiwanese patients who had attempted suicide: a grounded theory study. J Adv Nurs. 2008;62(1):53-61. doi:10.1111/j.1365-2648.2007.04578.x. [PubMed:
18352964].

34. Bridge JA, Goldstein TR, Brent DA. Adolescent suicide and suicidal behavior.JChild Psychol Psychiatry. 2006;47(3-4):372-94.doi:10.1111/j.14697610.2006.01615.x. [PubMed: 16492264].

35. Bazrafshan MR, Sharif F, Molazem Z, Mani A. Exploring the risk factors contributing to suicide attempt among adolescents: A qualitative study. Iran J Nurs Midwifery Res. 2016;21(1):93-9. doi: 10.4103/1735 9066.174747. [PubMed: 26985229].

36. Akbari M, Haghdoost AA, Nakhaee N, Bahramnejad A, Baneshi MR, Zolala F. Risk and protective factor for suicide attempt in Iran: a matched case-control study. Arch Iran Med. 2015;18(11):747-52. [PubMed: 26497371].

37. Moody C, Smith NG. Suicide protective factors among trans adults. Arch Sex Behav. 2013;42(5):739-52. doi: 10.1007/s10508-013-0099-8. [PubMed: 23613139].

38. Britton PC, Duberstein PR, Conner KR, Heisel MJ, Hirsch JK, Conwell Y. Reasons for living, hopelessness, and suicide ideation among depressed adults 50 years or older. Am J Geriatr Psychiatry. 2008;16(9):736-41. doi: 10.1097/JGP.0b013e31817b609a. [PubMed: 18757767].

39. Rafi Bazrafshan M, Sharif F, Molazem Z, Mani A. The effect of paternal addiction on adolescent suicide attempts: A qualitative study. Int J High Risk Behav Addict. 2016;5(3):22588. [PubMed: 27818961].

40. Herrera A, Dahlblom K, Dahlgren L, Kullgren G. Pathways to suicidal behaviour among adolescent girls in Nicaragua. Soc Sci Med 2006;62(4):805-14. doi: 10.1016/j.socscimed.2005.06.055. [PubMed: 16098648].

41. Keyvanara M, Haghighat M. Sociocultural contexts of attempting suicide among Iranian youth: a qualitative study. Eastern Mediterranean Health J. 2011;17(6):529-35.

42. Chioqueta AP, Stiles TC. The relationship between psychological buffers, hopelessness, and suicidal ideation: identification of protective factors. Crisis. 2007;28(2):67-73. doi:10.1027/0227-5910.28.2.67. [PubMed: 17722687].

43. Kushner HI, Sterk CE. The limits of social capital: Durkheim, suicide, and social cohesion. Am J Public Health. 2005;95(7):1139-43. doi: 10.2105/AJPH.2004.053314. [PubMed: 15933234].

44. Owens C, Booth N, Briscoe M, Lawrence C, Lloyd K. Suicide outside the care of mental health services: a case-controlled psychological autopsy study. Crisis. 2003;24(3):113-21. doi:10.1027/|0227-5910.24.3.113. [PubMed: 14518644].

45. Ebrahimi H, Namdar $\mathrm{H}$, Vahidi M. Mental illness stigma among nurses in psychiatric wards of teaching hospitals in the north-west of Iran. Iran J Nurs Midwifery Res. 2012;17(7):534-8. [PubMed: 23922602].

46. Leane W, Shute R. Youth suicide: the knowledge and attitudes of Australian teachers and clergy. Suicide Life Threat Behav. 1998;28(2):165-73. [PubMed: 9674076].

47. Mason KE, Polischuk P, Pendleton R, Bousa E, Good R, Wines JD. Clergy referral of suicidal individuals: a qualitative study. J Pastoral Care Counsel. 2011;65(3-4):1-11. doi: 10.1177/154230501106500304. [PubMed: 22452143]. 